\title{
Kinderurologie en concentratie van zorg; kijk over de grenzen!
}

\author{
W. F. J. Feitz ${ }^{1}$
}

Published online: 6 September 2017

(C) The Author(s) 2017. This article is an open access publication.

Samenvatting In de discussie over de concentratie van zorg zijn verschillende nieuwe ontwikkelingen te herkennen. In dit overzicht wordt een toelichting gegeven op de ontwikkelingen van het superspecialisme kinderurologie, de nationale expertisecentra en de Europese Reference Networks.

Trefwoorden kinderurologie - transitie van zorg · expertisecentrum · European Reference Networks

\section{Paediatric urology and concentration of care across the border!}

\begin{abstract}
In the discussion on the concentration of care are currently different aspects to be recognized. In this short overview an explanation is given on the developments of the super specialty training in paediatric urology, the National expertise centres and the European Reference Networks.
\end{abstract}

Keywords paediatric urology $\cdot$ transition of care · expertise centre · European Reference Networks

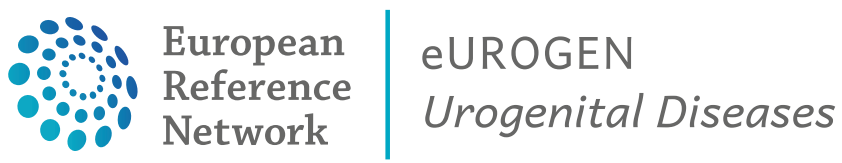

Prof. dr. W. F. J. Feitz

wout.feitz@radboudumc.nl

1 afdeling Urologie, Radboud Universitair Medisch Centrum, Nijmegen, Nederland

\section{Introductie}

Hoe zit het met de kinderurologie en concentratie van zorg? Deze vraag is makkelijk gesteld, moeilijk te beantwoorden en vanuit verschillende perspectieven te bekijken.

De superspecialisatie kinderurologie heeft zich de afgelopen decennia op verschillende vlakken ontwikkeld en heeft de laatste jaren een duidelijke erkenning gekregen binnen het urologische veld en, meer recent, ook binnen de kinderchirurgie. Het tweejarige fellowship kinderurologie is toegankelijk vanuit zowel de basisopleiding urologie als de basisopleiding kinderchirurgie; kinderurologen in $\mathrm{Ne}$ derland en Europa hebben dan ook momenteel niet allemaal dezelfde achtergrond. Daarnaast loopt de duur van de zorgtrajecten binnen de kinderurologie sterk uiteen. Voor sommige patiënten is een zorgtraject levenslang, en dus inclusief de transitie naar de volwassenenurologie. Dit maakt het noodzakelijk om een duidelijker beeld van de kinderurologie en van de recente ontwikkelingen daarbinnen te scheppen.

Er zijn meerdere niveaus te onderscheiden in de kennisconcentratie van de kinderurologie.

\section{De persoonlijke concentratie van zorg}

Persoonlijke concentratie van zorg is binnen het veld van de Nederlandse urologie al decennialang zichtbaar, doordat verschillende urologen zich verder gespecialiseerd hebben in de superspecialisatie kinderurologie. Deze specialisatie vond doorgaans plaats in de universitaire centra. Oorspronkelijk was het met name de persoonlijke interesse in de zorg voor kinderen en volwassenen met een aangeboren aandoening van de tractus urogenitalis die een grote rol speelde. 
De eerste kennis werd vooral opgedaan in buitenlandse centra in de Verenigde Staten, Engeland en Duitsland.

\section{Concentratie binnen specifieke centra}

Een ander niveau van concentratie is die binnen specifieke centra. Op verschillende afdelingen urologie in de academische ziekenhuizen, in vrijstaande kinderziekenhuizen en later in universitair medische centra, ontstond er door de hiervoor beschreven superspecialisatie een verschuiving in de invulling van de praktijk rond de zorg voor kinderen. Door de toename van de specialisatie en erkenning daarvan, werden de afdelingen groter en nam ook het aantal kinderurologen toe.

\section{Regionale concentratie}

Weer een ander niveau betreft de concentratie van de kinderurologie in de regio. Oorspronkelijk werd een groot deel van de kinderurologiezorg niet alleen in academische centra of vrijstaande kinderziekenhuizen, maar ook in grotere perifere ziekenhuizen uitgevoerd door urologen met speciale aandacht hiervoor. In een aantal topklinische ziekenhuizen zijn deze urologen binnen maatschappen de contactpersoon voor kinderartsen en andere specialisten. Momenteel vindt er met name een verschuiving van de zorg plaats bij pensionering van deze ervaren urologen. Ook is regionaal een verschuiving opgetreden na het aanscherpen van de eisen voor de anesthesie bij kinderen. Een deel van de regionale verschuiving wordt gekanaliseerd doordat de urologische Onderwijs- en Opleidingsregio's zijn gekoppeld aan de universitair medische centra.

\section{Landelijke concentratie}

In Nederland spelen verschillende recente ontwikkelingen een rol bij de concentratie van de kinderurologische zorg op nationaal niveau: 1) De erkenning van de Nederlandse Vereniging voor Urologie (NVU) van de kinderurologie als superspecialisatie [1]. 2) Het feit dat de NVU de eisen van het fellowship van de Joint Committee on Paediatric Urology (JCPU) voor de erkenning als kinderuroloog heeft overgenomen. 3) De vaststelling door de NVU van de Normering Urologische Behandelingen 2014 voor de kinderurologie [1]. 4) De ondersteuning door de NVU van de Nederlandse Hypospadiestudie voor de kwaliteitsaspecten van de kinderurologiezorg.

Deze ontwikkelingen en de huidige omschrijvingen lijken ook invloed te hebben op de werkwijze in de verschillende urologische maatschappen en de medisch-specialisti- sche bedrijven, en op de zorginkoop door zorgverzekeraars, maar een duidelijk overzicht is momenteel niet beschikbaar.

Recentelijk heeft er in Nederland een erkenningsronde plaatsgevonden inzake de behandeling van zeldzame aandoeningen, inspelend op de Europese ontwikkelingen voor patiënten met een zeldzame aandoening. Na toetsing door een onafhankelijke commissie en na consultatie van betrokken patiëntenverenigingen (indien beschikbaar) zijn, op ziektebeeldspecifiek niveau, de erkenningen toegewezen aan de verschillende expertisecentra door de Minister voor Volksgezondheid, Welzijn en Sport. Een lijst van deze centra is gepubliceerd door de Nederlandse Federatie van Universitair Medische Centra (NFU) [2] en een aanvullende erkenning vanuit patiëntenverenigingen vindt momenteel plaats door het initiatief 'Expertise in Kaart' [3].

\section{Concentratie van de opleiding kinderurologie}

Oorspronkelijk werd de specifieke kennis over de kinderurologie met name opgedaan in het buitenland, zoals hiervoor aangegeven. Persoonlijke beurzen vanuit het ziekenhuis of vanuit de Nierstichting maakten het voor sommige urologen mogelijk om langere tijd in het buitenland te verblijven. Momenteel is de situatie duidelijk veranderd door de ontwikkeling binnen de European Society for Pediatric Urology (ESPU) en de European Union of Medical Specialists (EUMS). Samen met de European Pediatric Surgery Association (EUPSA) en de European Board of Urology (EBU) bestaat er nu een Joint Committee for Pediatric Urology (EUMS/JCPU 6) [4]. Vanuit deze board zijn verschillende Europese Kinderurologiecentra erkend voor een fellowship kinderurologie. Momenteel betreft dit 25 centra die over heel Europa verspreid liggen, met als Nederlandse locaties Groningen, Nijmegen en Utrecht.

\section{Concentratie vanuit de patiënten}

Voor verschillende kinderurologische ziektebeelden bestaan er patiëntenverenigingen, maar zeker niet voor allemaal. Het betreft met name de Nierpatiënten Vereniging Nederland (urethrakleppen) [5] en de Patiëntenvereniging voor Blaasextrophie Nederland [6]. Momenteel is er ook een Europese overkoepelende organisatie van patiëntenverenigingen EURORDIS [7], waarvan deelnemers als Patient Advocacy Group (ePAG) in verschillende Europese organisaties participeren. De ePAG-vertegenwoordigers zijn ook op alle niveaus betrokken bij de European Reference Networks (ERN) for rare diseases and complex conditions [8]. 


\section{Europese concentratie van zorg}

Op Europees niveau speelt de visie 'Delen, Zorg en indien mogelijk Genezen' (Share, Care, Cure) duidelijk een nieuwe rol in de Europese innovatie van de gezondheidszorg. In de afgelopen twee decennia zijn er organisatorisch, juridisch en wetenschappelijk voorbereidingen getroffen, die na zes jaren van operationalisering nu werkelijkheid zijn geworden. Voor patiënten met zeldzame aandoeningen en complexe situaties zijn er op dit moment 24 Europese netwerken, waarin meer dan 300 ziekenhuizen en 900 expertiseteams participeren [8]. Daarbij is ook een structuur opgezet voor samenwerking met de European Patient Advocacy Groups (EPAGs) van EURORDIS op alle niveaus van organisatie, uitkomstbepalingen en evaluaties [7].

Vanuit de EAU is drie jaar geleden een kleine groep betrokkenen gestart met de ontwikkeling van een applicatie voor het aanvragen van een European Reference Network for rare urogenital diseases and complex conditions (ERN eUROGEN) [9]. Het eUROGEN-netwerk is inmiddels een feit, want op 8 maart 2017 heeft het netwerk de erkenning ontvangen vanuit de Europese Unie op de $3 r d$ ERN Conference in Vilnius, Litouwen [10]. In het netwerk participeren momenteel 29 ziekenhuizen mét hun erkende expertiseteams vanuit 11 Europese landen.

De opzet en intentie van eUROGEN zijn het faciliteren van levenslange zorg voor patiënten met een zeldzame of complexe urogenitale aandoening en een goede transitie van zorg voor diegenen die dat nodig hebben. Dit omvat een breed scala aan aspecten, waarbij wordt gefocust op de specifieke termen Share, Care and Cure. Een van die aspecten is de cross-borderconsultatie, waarvoor een specifiek IT-platform beschikbaar is gesteld door de EU, met specifieke Europese informed-consentformulieren. Een ander aspect is de continuering van zorg door middel van specifieke opleiding en onderwijsinitiatieven, en de ontwikkeling van guidelines en ziektebeeldgerelateerde onderzoekprogramma's. De organisatie eUROGEN heeft een strategic board en een advisory board. Momenteel zijn 16 ziektebeelden en complexe aandoeningen ondergebracht in drie werkstromen: rare congenital uro-recto-genital anomalies, functional urogenital conditions requiring higly specialised surgery en rare urogenital tumours. Meer informatie hierover is beschikbaar via de EAU- en ERN-websites.

\section{Conclusie}

De verschillende aspecten die een rol spelen bij centralisatie, kinderurologie en concentratie van zorg, maar - veel belangrijker - het delen van kennis, zorg en waar mogelijk het bereiken van genezing, vormen een zich uitbreidend netwerk. Dit netwerk zal in de komende jaren verder ontwikkeld worden, zodat uiteindelijk elk Europees land en alle expertiseteams voor de zorg aan specifieke patiënten hierbij zullen zijn aangesloten. De impact van Brexit is in deze nog onduidelijk.

De patiënten met urologische aandoeningen, leden van de NVU en de toekomstige kinderurologen in Nederland zullen kunnen gaan profiteren van deze nieuwe interacties in de verschillende netwerken, Europese organisaties en te verwachten innovaties, met ieder hun eigen inbreng en ontwikkelingen.

Open Access This article is distributed under the terms of the Creative Commons Attribution 4.0 International License (http:// creativecommons.org/licenses/by/4.0/), which permits unrestricted use, distribution, and reproduction in any medium, provided you give appropriate credit to the original author(s) and the source, provide a link to the Creative Commons license, and indicate if changes were made.

\section{Literatuur}

1. NVU. Normering Urologische Behandelingen 2014 voor de Kinderurologie. Definitief, versie december 2014. NVU bestuursbesluit 2014 kinderurologie. 2014. www.nvu.nl. Geraadpleegd op: 19 jul 2017.

2. NFU Minister erkenning expertisecentra zeldzame aandoeningen. Beschikbaar via: http://www.nfu.nl/actueel/minister-erkentexpertisecentra-zeldzame-aandoeningen, http://www.nfu.nl/img/ pdf/Expertisecentra_Eerste_tranche_Grp_A-D_v18-11-2015.pdf en http://www.nfu.nl/img/pdf/Expertisecentra_Tweede_tranche_ Grp_E_v18-11-2015.pdf. Geraadpleegd op: 9 jul 2017.

3. Expertise in kaart. Expertise in kaart. 2015. https://www. expertiseinkaart.nl/. Geraadpleegd op: 9 jul 2017.

4. EUMS/JCPU. The goal of the Joint Committee of Paediatric Urology and the European Academy of Paediatric Urology is to set a high standard of care for children with problems of the urinary and genital tract by setting standards for clinical caretakers of these children. 2017. https://www.espu.org/eapu-jcpu. Geraadpleegd op: 9 jul 2017.

5. Nierpatiënten Vereniging Nederland. https://www.nvn.nl/home. Geraadpleegd op 9 juli 2017.

6. Patiëntenvereniging voor Blaasextrophie Nederland. Beschikbaar via: http://www.blaasextrophy.nl/ en https://www.nvn.nl/ nierziekten-en-behandeling/behandeling/expertisecentra. Geraadpleegd op: 9 jul 2017.

7. Eurordis. EURORDIS. 2017. http://www.eurordis.org/. Geraadpleegd op: 9 jul 2017.

8. ERN. Beschikbaar via: http://ec.europa.eu/health/ern/scope_en. Geraadpleegd op: 9 jul 2017.

9. ERN eUROGEN. European Reference Network on urogenital diseases and conditions. 2017. http://ec.europa.eu/health/sites/ health/files/ern/docs/erneurogen_factsheet_en.pdf. Geraadpleegd op: 9 jul 2017.

10. ERN. ERN 3rd Conference on ERN report. 2017. http://ec. europa.eu/health/sites/health/files/ern/docs/ev_20170309_frep_en. pdf. Geraadpleegd op: 9 jul 2017.

Prof. dr. W.F.J. Feitz kinderuroloog 